\title{
INCIDENCE RATE AND BURDEN OF ILLNESS AT THE PYEONGCHANG 2018 PARALYMPIC WINTER GAMES
}

"The corresponding author has the right to grant on behalf of all authors and does grant on behalf of all authors, an exclusive licence (or non exclusive for government employees) on a worldwide basis to the BMJ Publishing Group Ltd and its licensees to permit this article (if accepted) to be published in Journal (British Journal of Sports Medicine) editions and any other BMJPGL products to exploit all subsidiary rights, as set out in our license.”

\section{Address for correspondence}

Professor Wayne Derman

Institute of Sport and Exercise Medicine

Division of Orthopaedic Surgery

Faculty of Medicine and Health Science

Room 4019, $4^{\text {th }}$ Floor, Clinical Building

Tygerberg Medical Campus

Francie van Zijl Drive, Bellville, Cape Town, 7505

\section{Keywords}

Paralympic, impairment, disability, illness, burden, international sporting events, athletes

\section{What are the new findings?}

- This was the first study to document both the incidence rate and burden of illness per 1000 athlete days at a Winter Paralympic Games

- The sport with the highest incidence rate of illness was Para snowboard, and illnesses were most commonly reported in the skin and subcutaneous system in this sport

- Illnesses were most common in the respiratory system, skin and subcutaneous system and eye and ocular adnexa. The burden of illness was highest in the respiratory system

\section{How might this impact on clinical practice in the near future?}

- The data presented in the current study illustrate the physiological systems and sports most at risk for illness, and can be used to inform coaches and organisations in their measures to avoid illness in their teams at Paralympic Winter Games 
- These data also provide the basis for organised illness prevention programs in sports and organisations 


\section{ABSTRACT}

Objective: To describe the incidence rate and burden of illness at the Pyeongchang 2018 Paralympic Winter Games.

Methods: A total of 567 athletes from 49 countries were monitored for 12 days over the Pyeongchang 2018 Games (6804 athlete days). Illness data were obtained daily from teams with (41 teams, 557 athletes) and teams without ( 8 teams, 10 athletes) their own medical support, through electronic data capturing systems.

Results: There were 87 illnesses reported, with an illness incidence rate (IR) of 12.8 illnesses per 1000 athlete days (95\% CI 10.2-16.0) and illness burden (IB) of 6.8 days lost per 1000 athlete days (95\% CI 3.4- 13.5). The highest IR was reported for Para snowboard (IR of 19.7 (95\% CI 12.0-32.2)). Illnesses in the respiratory system (IR of 4.1 (95\% CI $2.9-5.9)$, IB of 1.4 (95\% CI 0.6- 3.0)) skin and subcutaneous system (IR of 2.5 (95\% CI 1.5- 4.1), IB of 0.6 (95\% CI 0.1-2.9)), and eye and ocular adnexa (IR of 1.6 (95\% CI 0.9- 3.1), IB of 0.5 (95\% CI $0.1-3.3)$ ) were the most common.

Conclusion: This is the first study to report both the incidence rate and burden of illness in this setting. There was a high incidence rate of illness in the new sport of Para snowboard. The respiratory system had both the highest incidence rate and burden of illness. 


\section{INTRODUCTION}

In recent years, there has been an increase in the number of studies, development of systems and improved data collection methods regarding the surveillance of illness in athletes with impairment at major international multi-sport competitions. The International Paralympic Committee (IPC) has prioritised epidemiological research regarding the protection of the health of the Para athlete and has committed to ongoing research in this area.[1-5]

The first robust epidemiological investigation of illness in athletes with impairment in a Paralympic Games setting was conducted at the London 2012 Paralympic Games.[2,5] The London 2012 and subsequent Rio 2016 Summer Games studies documented an incidence rate of illness (IR) of 12.8 (95\% CI 12.1 to 14.2)[1] and 10.0 (95\% CI 9.2 to 10.9)[4] illnesses per 1000 athlete days, respectively. The first such investigation in a Winter Games setting was conducted at the Sochi 2014 Paralympic Winter Games. The IR of illness was 18.7 (95\% CI 15.1 to 23.2), indicating a higher risk of illness in the Winter Games setting.[6] At Sochi 2014, the sport with the highest IR of illness was wheelchair curling (IR of 20.0 (95\% CI 10.1 to 39.6)), and there were more illnesses reported in athletes aged $35-63$ years (IR of 22.6 (95\% CI 16.0 - 31.9)). The physiological systems most affected by illness were the respiratory system (IR of 5.6 (95\% CI 3.8 to 8.0)), eye and ocular adnexa (IR of 2.7 (95\% CI 1.7 to 4.4 )) and digestive system (IR of 2.4 (95\% CI 1.4 to 4.2$)$ ). [6]

Longitudinal illness surveillance is important via repeated measures at multiple Games, or out of the Games setting, to indicate which areas of the health of the Para athlete require attention, intervention and further monitoring.[7] This is one in a series of studies required to further elucidate the patterns of illness in the Paralympic Games setting.

We aimed to document the incidence rate and burden of illness at the Pyeongchang 2018 Paralympic Winter Games. This study aimed to report overall illness incidence rate, illness incidence rate per sport, type of illness and physiological systems affected by the illness in the three-day pre-competition and nine-day competition period of the Games.

\section{METHODS}


The present study was a component of a larger ongoing epidemiological study of both the Summer and Winter Paralympic Games, which commenced with the London 2012 Paralympic Games. This study involved prospective monitoring of the epidemiology of illness during the three-day pre-competition period and nine-day competition period of the Pyeongchang 2018 Paralympic Winter Games. Athletes participated in five categories of sports, namely Para alpine skiing, Para snowboard, Para Nordic skiing (combining Para cross country skiing and Para biathlon), Para ice hockey and wheelchair curling.

\section{Participants}

The current study was conducted by members of the International Paralympic Committee (IPC)'s Medical Committee. Ethical approval for this study was granted by both the University of Brighton (FREGS/ES/12/11) and Stellenbosch University (N16/05/067) Research Ethics Committees before research activities were conducted. During the registration process, consent was obtained from all athletes for the use of de-identified medical data gathered during the Games.

Teams who had their own medical support at the Games utilised the web-based injury and illness surveillance system (WEB-IISS) in order to record illnesses, which has been successfully used at the London 2012, Sochi 2014 and Rio 2016 Paralympic Games.[1,4,8] A more detailed description of the WEB-IISS can be found in the previous literature.[8] Introductory information about the study was provided prior to the Games via email to all National Paralympic Committees (NPCs) chefs de mission $(n=49)$, and further communication was sent to all team physicians of the teams competing at the Games $(n=41)$. During the precompetition period of the Games, a medical briefing was held where team physicians were provided with both detailed information about the study, as well as individualised training sessions on how to use the WEB-IISS. Daily data entry compliance was incentivised by the provision of a basic tablet computer (Samsung, Seoul, Korea) to each participating country that had medical support at the Games, which could be used for data entry. Countries with accompanying medical staff who had less than five athletes in their team reported their data through the same portal used on the tablets, via laptop computers and wireless internet connections within the Paralympic Village.

For teams who did not have accompanying medical staff, illness data were captured via the Pyeongchang Organizing Committee for the 2018 Olympic \& Paralympic Winter Games 
(POCOG) customised surveillance system in the local organising committee's venue and polyclinic facilities. This system was also used to capture all admissions to peripheral hospitals, radiology services, medical and pharmacy encounters, and specialist services at both the polyclinic and venues. It additionally captured visits from athletes with their own medical support services who chose to report their illnesses to the polyclinic. After the closing of the Games, these data were de-linked and processed to remove duplicate entries and data from non-athletes. Furthermore, physiotherapy, non-ophthalmological routine eye examinations (optometry) or orthopaedic bracing visits to the polyclinic during this time were excluded. These data were then integrated into the WEB-IISS illness master spreadsheet for analysis. Thus, the present study constitutes all illnesses presented to team physicians and local polyclinic staff during the Games period of the Pyeongchang 2018 Paralympic Winter Games.

\section{Definition of illness}

An illness that should be reported to the team physician was defined as 'any athlete requiring medical attention for an illness regardless of the consequences with regard to absences from training or competition', and more specifically defined as 'any newly acquired illness as well as exacerbations of pre-existing illness that occurred during training and/or competition in the pre-competition or competition periods of the Pyeongchang 2018 Paralympic Winter Games.' [8]

\section{Calculation of athlete days}

The team physicians involved in this study were asked to report team size per day at the same time as they reported any illnesses. However, these data did not differ from the masterlist of athletes attending the Games, which was published by the IPC prior to the Games. We therefore used the published list, as all team sizes (both WEB-IISS and polyclinic monitored athletes) came from the same source and were seen to be reliable in comparison to physician reported team size. Athlete days were calculated by multiplying the total term days (three-day precompetition and nine-day competition period) multiplied by team size as published by the IPC. These data constituted denominator data for the calculation of illness incidence rate (IR). The provision of accurate denominator data is critical to correct analysis and reporting of the epidemiology of illness in this international multi-sport setting, with multiple teams.

\section{Calculation of the illness incidence rate}


The illness IR was reported as illnesses per 1000 athlete days $(95 \% \mathrm{CI})$. Athlete days were reported separately by sex, age group, sport and Games periods. Total illnesses as well as illnesses in different sports and physiological systems were reported. The percentage of athletes with an illness was calculated by dividing the total number of athletes with an illness by the total number of athletes competing in the relevant sub group. This was then multiplied by 100 .

\section{Calculation of time loss and illness burden}

Time loss as a result of illness was estimated by the team physician at the time of reporting the illness. The doctors were then able to log into the system at a later stage and modify the entry to represent the actual days lost by the athlete.

The illness burden (IB) was determined by calculating the number of days lost per illness, per 1000 athlete days, thus accounting for both frequency (incidence rate) and severity (time loss) of illness. The IB was expressed as days lost per 1000 athlete days $(95 \% \mathrm{CI})$.[9,10]

Time loss data (and subsequent IB calculations) were only available for illnesses logged on the WEB-IISS. Thus, the time loss and IB denominator data represented 557 athletes $(83.6 \%)$ who had their own medical support (6684 athlete days).

\section{Statistical analysis of the data}

All data (WEB-IISS and polyclinic datasets) were in the form of counts (i.e. the number of illnesses each athlete reported). A description of the impairment categories of athletes with an illness was presented as percentage of the total ill athlete cohort (\%) only. This is because the impairment data of the total athlete cohort participating at the Games was not available and the incidence rates could not be reported for impairment categories. Some athletes participated in more than one sport and/or more than one event; the primary sport of the athlete (determined from the IPC masterlist of athletes attending the Games) was used in the analysis. Where some athletes incurred multiple illnesses during the total Games period, each of these were reported as distinct illnesses. Descriptive statistical analyses were reported, including number of athletes participating in five categories of sport (Para alpine skiing, Para snowboard, Para Nordic skiing (combining Para cross country skiing and Para biathlon), Para ice hockey and wheelchair curling), number of athletes competing by age (12-25 years, 26-35 years and 35-67 years) and sex (male or female), number of reported illnesses and number and percentage of athletes with an illness. Generalized linear Poisson regression modelling (multiple independent 
models developed with one independent variable each; SAS 9.4) was used to model the number of reported illnesses overall, as well as the number of illnesses for physiological systems affected by an illness and were corrected for overdispersion and including the independent variables of interest. All results reported were from univariate Poisson models, and included a scale parameter, due to some modest overdispersion in the Poisson models. No inclusion of covariables in the models were made. Illness incidence rates (IR) and illness burden (IB) were reported per 1000 athlete days (including 95\% confidence intervals). The incidence rate of illness was reported by sex, age group, type of sport and physiological system affected by illness, and the illness burden for physiological system affected.

\section{RESULTS}

\section{Participants}

The present study details all illnesses presented to team physicians and local polyclinic staff during the pre-competition and competition periods of the Pyeongchang 2018 Paralympic Winter Games. The total number of countries attending the Games was 49, representing 567 athletes constituting 6804 athlete days. The complete cohort of athletes at the Games was monitored in this study. There were 41 teams (83.6\% of all teams) representing 557 athletes (6684 athlete days) who had their own medical support, whilst 8 countries (16.4\% of all teams) representing 10 athletes (120 athlete days) utilised only the local polyclinic medical facilities. If an athlete was monitored on the WEB-IISS also utilised polyclinic services and the illnesses recorded were the same, only the WEB-IISS encounter was included.

There were 433 male and 134 female athletes monitored in the study. The mean $( \pm$ SD) age of all athletes in this study was $32.1 \pm 10.3$ years. Total numbers of athletes, and sex and age distribution in five categories of sports, namely Para alpine skiing, Para snowboard, Para Nordic skiing (combining Para cross country skiing and Para biathlon), Para ice hockey and wheelchair curling is presented in Table 1.

Table 1: Number of athletes (all athletes at the Games) participating in each sport at the Pyeongchang 2018 Paralympic Winter Games

\begin{tabular}{lllllll}
\hline Sport & All athletes & Males & Females & Age 13-25 & Age 26-35 & Age 36-67 \\
\hline All & 567 & 433 & 134 & 161 & 216 & 190
\end{tabular}




\begin{tabular}{lllllll} 
Para Nordic skiing & 159 & 100 & 59 & 52 & 73 & 34 \\
Para alpine skiing & 141 & 101 & 40 & 59 & 53 & 29 \\
Para ice hockey & 135 & 134 & 1 & 29 & 52 & 54 \\
Para snowboard & 72 & 58 & 14 & 20 & 30 & 22 \\
Wheelchair curling & 60 & 40 & 20 & 1 & 8 & 51 \\
\hline
\end{tabular}

\section{Incidence rate of illness by sport}

Table 2 presents the total number of illnesses, as well as illnesses reported in five categories of sports. The total number of illnesses recorded in all sports was 87 illnesses (65 WEB-IISS, 22 polyclinic) in 77 athletes (13.6\% of all athletes at the Games), with an IR of 12.8 per 1000 athlete days (95\% CI 10.2 to 16.0)). There was a higher IR of new illnesses (IR of 11.3 (95\% CI 8.9 to 14.4)) compared with recurrent illnesses (IR of 1.5 (95\% CI 0.7 to 2.9)). The highest total number of illnesses were recorded in the sports of Para Nordic skiing (23 illnesses in 20 athletes) and Para ice hockey (23 illnesses in 21 athletes), although the sport of Para snowboard had the highest IR of 19.7 illnesses per 1000 athlete days (95\% CI 12.0 to 32.2). The lowest IR was recorded for wheelchair curling, where 5 illnesses were reported in 5 athletes (IR of 6.9 (95\% CI 2.8 to 17.3$)$. There were no significant differences in IR between the sports.

Table 2: Incidence rate of illness by sport for athletes competing at the Pyeongchang 2018 Paralympic Winter Games

\begin{tabular}{lllllll}
\hline Sport & $\begin{array}{l}\text { Total } \\
\text { number } \\
\text { of }\end{array}$ & $\begin{array}{l}\text { Number } \\
\text { of } \\
\text { athletes }\end{array}$ & $\begin{array}{l}\text { Total } \\
\text { number of } \\
\text { athletes }\end{array}$ & $\begin{array}{l}\text { Total } \\
\text { number } \\
\text { of }\end{array}$ & $\begin{array}{l}\text { Percentage } \\
\text { of athletes } \\
\text { with an }\end{array}$ & $\begin{array}{l}\text { Illness incidence } \\
\text { rate: }\end{array}$ \\
& & illnesses/1000 \\
illness & & $\begin{array}{l}\text { competing } \\
\text { athlete } \\
\text { days }\end{array}$ & illness (\%) & $\begin{array}{l}\text { athlete days } \\
\text { (95\% CI) }\end{array}$ \\
\hline All & 87 & 77 & 567 & 6804 & 13.6 & $12.8(10.2-16.0)$ \\
Para snowboard & 17 & 13 & 72 & 864 & 18.1 & $19.7(12.0-32.2)$ \\
Para ice hockey & 23 & 21 & 135 & 1620 & 15.6 & $14.2(9.3-21.7)$ \\
Para Nordic skiing & 23 & 20 & 159 & 1908 & 12.6 & $12.1(7.9-18.5)$ \\
Para alpine skiing & 19 & 18 & 141 & 1692 & 12.8 & $11.2(7.0-17.9)$ \\
Wheelchair curling & 5 & 5 & 60 & 720 & 8.3 & $6.9(2.8-17.3)$ \\
\hline
\end{tabular}

\section{Incidence rate of illness by sex and age group}

The incidence rate of illness by sex and age group is presented in Table 3. There were no significant differences in IR between males and females, and between age groups. 
Table 3: Incidence rate of illnesses by sex and age group for athletes competing at the Pyeongchang 2018 Paralympic Winter Games

\begin{tabular}{|c|c|c|c|c|c|c|}
\hline Sex/Age group & $\begin{array}{l}\text { Total } \\
\text { number } \\
\text { of } \\
\text { illnesses }\end{array}$ & $\begin{array}{l}\text { Number } \\
\text { of } \\
\text { athletes } \\
\text { with an } \\
\text { illness }\end{array}$ & $\begin{array}{l}\text { Total } \\
\text { number of } \\
\text { athletes } \\
\text { competing }\end{array}$ & $\begin{array}{l}\text { Total } \\
\text { number of } \\
\text { athlete } \\
\text { days }\end{array}$ & $\begin{array}{l}\text { Percentage } \\
\text { of athletes } \\
\text { with an } \\
\text { illness (\%) }\end{array}$ & $\begin{array}{l}\text { Illness incidence } \\
\text { rate: illnesses/1000 } \\
\text { athlete days }(95 \% \\
\text { CI) }\end{array}$ \\
\hline All & 87 & 77 & 567 & 6804 & 13.6 & $12.8(10.2-16.0)$ \\
\hline Male & 62 & 54 & 433 & 5196 & 12.5 & $11.9(9.2-15.6)$ \\
\hline Female & 25 & 23 & 134 & 1608 & 17.2 & $15.6(10.2-23.6)$ \\
\hline Age 13 to 25 years & 24 & 22 & 161 & 1932 & 13.7 & $12.4(8.2-18.9)$ \\
\hline Age 26 to 35 years & 28 & 26 & 216 & 2592 & 12.0 & $10.8(7.3-16.0)$ \\
\hline Age 36 to 67 years & 35 & 29 & 190 & 2280 & 15.3 & $15.4(10.8-21.8)$ \\
\hline
\end{tabular}

Incidence rate of illness in the pre-competition ( 3 days) and competition period ( 9 days)

There were 28 illnesses recorded in 25 athletes (IR of 16.5 (95\% CI 10.9 to 24.9)) during the pre-competition period, and 59 illnesses recorded in 54 athletes (IR of 11.6 (95\% CI 8.8 to 15.1)) during the competition period of the Pyeongchang 2018 Paralympic Winter Games (table 4). There was no significant difference of incidence rate of illness between these two Games periods.

Table 4: Incidence rate of illness in the pre-competition and competition periods for athletes competing at the Pyeongchang 2018 Paralympic Winter Games

\begin{tabular}{|c|c|c|c|c|c|c|}
\hline Period & $\begin{array}{l}\text { Total } \\
\text { number of } \\
\text { illnesses }\end{array}$ & $\begin{array}{l}\text { Number } \\
\text { of athletes } \\
\text { with an } \\
\text { illness }\end{array}$ & $\begin{array}{l}\text { Total } \\
\text { number of } \\
\text { athletes } \\
\text { competing }\end{array}$ & $\begin{array}{l}\text { Total } \\
\text { number of } \\
\text { athlete } \\
\text { days }\end{array}$ & $\begin{array}{l}\text { Percentage } \\
\text { of athletes } \\
\text { with an } \\
\text { illness (\%) }\end{array}$ & $\begin{array}{l}\text { Illness incidence rate: } \\
\text { illnesses/1000 athlete } \\
\text { days }(95 \% \mathrm{CI})\end{array}$ \\
\hline All & 87 & 77 & 567 & 6804 & 13.6 & $12.8(10.2-16.0)$ \\
\hline Pre-competition & 28 & 25 & 567 & 1701 & 4.4 & $16.5(10.9-24.9)$ \\
\hline Competition & 59 & 54 & 567 & 5103 & 9.5 & $11.6(8.8-15.1)$ \\
\hline
\end{tabular}

\section{Incidence rate of illness for each physiological system}

The physiological systems affected by illness are presented in Table 5 . The respiratory system had the highest number of illnesses reported, with 28 illnesses reported in 28 athletes (IR of $4.1(95 \%$ CI 2.9 to 5.9$)$. The second most commonly affected system was the skin and 
subcutaneous system with 17 illnesses reported in 16 athletes (IR of 2.5 (95\% CI 1.5 to 4.1 ). The eye and ocular adnexa (surrounding tissues) had an IR of 1.6 (95\% CI 0.9 to 3.1), with 10 athletes reporting 11 illnesses.

Table 5: Incidence rate of illness in each physiological system for athletes competing at the Pyeongchang 2018 Paralympic Winter Games

\begin{tabular}{lllll}
\hline Physiological system & $\begin{array}{l}\text { Total number } \\
\text { of illnesses }\end{array}$ & $\begin{array}{l}\text { Number of } \\
\text { athletes with } \\
\text { an illness }\end{array}$ & $\begin{array}{l}\text { Percentage } \\
\text { of athletes } \\
\text { with an } \\
\text { illness (\%) }\end{array}$ & $\begin{array}{l}\text { Illness incidence } \\
\text { rate: } \\
\text { illnesses/1000 } \\
\text { athlete days }(\mathbf{9 5 \%} \\
\text { CI) }\end{array}$ \\
\hline All & & & & $12.8(10.2-16.0)$ \\
Respiratory & 87 & 77 & 13.6 & $4.1(2.9-5.9)$ \\
Skin and subcutaneous & 28 & 28 & 4.9 & $2.5(1.5-4.1)$ \\
Eye and ocular adnexa & 17 & 16 & 2.8 & $1.6(0.9-3.1)$ \\
Digestive & 11 & 10 & 1.8 & $1.3(0.7-2.5)$ \\
Genitourinary & 9 & 9 & 1.6 & $0.9(0.4-2.0)$ \\
Nervous & 6 & 6 & 1.1 & $0.9(0.3-2.5)$ \\
\hline
\end{tabular}

\section{Illness by impairment}

Table 6 depicts the impairment profiles of 59 athletes with illnesses, whose data were captured on the WEB-IISS. Illnesses provided by the polyclinic did not provide impairment details of the ill athletes. Among the 59 athletes, there were 26 athletes with limb deficiency (44\%), followed by 16 with spinal cord injury $(27.1 \%)$.

Table 6: A description of the impairment types of the 59 athletes with an illness on the WEB-IISS at the Pyeongchang 2018 Paralympic Winter Games

\begin{tabular}{lll}
\hline Impairment type & $\begin{array}{l}\text { Number of athletes with } \\
\text { an illness }\end{array}$ & $\begin{array}{l}\text { Percentage of ill athletes in } \\
\text { each impairment type (\%) }\end{array}$ \\
\hline All & 59 & 100 \\
Limb deficiency (amputation, dysmelia, & 26 & 44 \\
congenital deformity) & & 27 \\
Spinal cord injury & 16 &
\end{tabular}




\section{Time loss and burden of illness}

Of the illnesses reported utilising the WEB-IISS during the Games period (6684 athlete days), $27.7 \%$ of the illnesses required one or more days of exclusion from training or competition, whilst $72.3 \%$ of illness on the WEB-IISS required no time loss from training or competition.

There were 18 illnesses that required one or more days absence from training/competition. The total days lost were 44, with an illness burden (IB) of 6.8 days lost per 1000 athlete days (95\% CI 3.4 to 13.5). The physiological system with the highest illness burden was the respiratory system (9 days lost; IB of 1.4 (95\% CI 0.6 to 3.0)), followed by the skin and subcutaneous system (IB of 0.6 (95\% CI 0.1 to 2.9)). The eye and ocular adnexa had an IB of 0.5 (95\% CI 0.1 to 3.3)) and the digestive system had a time loss burden of 0.3 days lost per 1000 athlete days $(95 \%$ CI 0.0 to 2.0$)$.

\section{DISCUSSION}

The present epidemiological study is the first to document both the incidence rate and burden of illnesses per 1000 athlete days in athletes with impairment at a major multi-sport Winter competition and constitutes a significant addition to the dataset of illness in this setting.

\section{Para snowboard a risk for all illnesses, and specifically skin illnesses}

The first important finding of this study was that the relatively new sport of Para snowboard was identified as high risk for all illnesses, and specifically illnesses in the skin and subcutaneous system.

The skin and subcutaneous system was affected by a high rate of illness (IR of 2.5 (95\% CI 1.5 to 4.1)) for all athletes at these Games. The conditions reported included stump/prosthesis interface pathology, stump/skin subcutaneous pain, skin rash, skin breakdown and abscesses. Specifically, athletes in the sport of Para snowboard reported more skin and subcutaneous 
illnesses (35\% of all illnesses in Para snowboard athletes; IR of 6.9 (95\% CI 3.1 to 15.6)) as opposed to skin injuries, lacerations and abrasions which are reported as injuries on the WEBIISS and will be described in a subsequent paper. The finding that stump/prosthesis interface pathology constituted a large component of these reported illnesses indicates the need for specific tailored interventions to target skin care in the groups of athletes with impairment competing in Para snowboard, predominantly athletes with limb deficiency, who constituted the largest number of ill athletes at these Games, (44\%).[5].

\section{Respiratory system still the highest at risk for illness}

The respiratory system was once again the system at highest risk for illness at these Games (IR of 4.1 (95\% CI 2.9 to 5.9)). This finding has been shown in previous studies and has been implicated in both Para and able-bodied athletes in both Summer and Winter Games settings.[2,4,5,8,11-13]

\section{The burden of illness in the Para athlete population}

A novel contribution of this study was the addition of illness burden calculations. In recent years, epidemiological injury and illness research has moved away from solely reporting incidence rate of illness, and toward a more complete understanding of the consequences of the reported condition. This has resulted in the description of both the number and subsequent burden of illnesses in studied populations, reported as time lost (severity) per illness.[9] The overall illness burden (IB) at the Pyeongchang 2018 Games was 6.8 days lost per 1000 athlete days (95\% CI 3.4 to 13.5 ), and the system with the highest IB was the respiratory system (IB of $1.4(95 \%$ CI 0.6 to 3.0$))$. It is interesting to note that the respiratory system had both a high incidence rate as well as high severity of illnesses, resulting in the highest burden. This is in accordance with previous studies which indicated respiratory illnesses pose a high risk to athletes during sporting activities.[2,4,5,8,12-14]

Previous research in the sporting realm has shown injury and illness burden in athletes, however most of these studies have been conducted in team sports and use the "athletes at risk" method which estimates exposure time as "the number of players on the field multiplied by the number of game-hours that the team has played", and reports illnesses per 1000 player hours.[9,14-21] This study has been conducted according to the "athlete participation" method, which assumes that "one athlete is participating in one practice or game" and reports illnesses per 1000 player days.[10] As a result, comparison to these studies in sports which report 
illnesses in very high risk team sports with different denominator statistics is not possible. This study constitutes the first study to report illness burden in this population using this method.

\section{The eye and ocular adnexa are at risk for illness in a Winter setting}

A novel finding at the Sochi Games was the high incidence rate of illness in the eye and ocular adnexa (surrounding tissues, IR of 2.7 (95\% CI 1.7 to 4.4)).[8] This finding has been confirmed in the current study (IR of 1.6 (95\% CI 0.9 to 3.1), IB of 0.5 (95\% CI 0.1 to 3.3)). The ocular pathologies reported by the team physicians and the POCOG (polyclinic) ophthalmologists for this system included allergic conjunctivitis, corneal erosion, degenerative myopia, dry eye and ocular hypertension, indicating a more diverse group of eye conditions in this setting which in turn indicates factors other than sun burn and snow glare should be considered. These findings warrant further detailed and longitudinal (continuous) investigation within a Winter sport athlete cohort, however it may be important to note that some of the athletes who may have reported these conditions were visually impaired, and thus a pre-exiting condition may be present.

\section{Lower rate of illness at Pyeongchang 2018 compared with Sochi 2014}

It is interesting to note that the overall IR of illness was lower at the Pyeongchang 2018 Games compared with the Sochi 2014 Games (IR of 18.7 (95\% CI 15.1 to 23.2).[8] Although a full analysis of this difference was not possible in the current study, a detailed analysis is planned to investigate this decrease in reported illnesses in a Winter setting, and determine factors relating to the observed difference.

\section{Strengths and limitations of the study}

A strength of the current study was that the data collection system was upgraded prior to these Games, so that medical officers could alter the days lost after the initial logging of the illness or injury. This facility was kept open for alterations to the time loss data to be made by the team physicians for a period of two weeks following the conclusion of the Games.

A limitation of the present study was that two electronic sources were used for data collection (WEB-IISS and polyclinic entries). The polyclinic data collection did not collect as much detailed data as the WEB-IISS. It is suggested that all athletes be covered on the WEB-IISS at future editions of the Games, or that the local organising committee system be expanded to include the same variables as the WEB-IISS. There was a relatively small total number of 
illnesses and ill athletes in the present study, which does not allow for complex multivariate statistical analysis. Furthermore, although this study captured impairment data from athletes who reported an illness, we did not know the entire cohort's impairment details, limiting the conclusions drawn about impairment in the present study.

\section{Summary and conclusion}

In summary, the present study was the second large dataset to present illnesses per 1000 athlete days at a Paralympic Games. We report a high incidence rate of illness in the new sport of Para snowboard, specifically illnesses in the skin and subcutaneous system. A novel finding of this study was the addition of illness burden calculations, which showed that the respiratory system has both a high incidence rate and burden of illness. Using these baseline data, further studies will investigate the difference in illness profile of the Sochi 2014 and Pyeongchang 2018 Games, and the factors related to this difference.

\section{ACKNOWLEDGEMENTS}

This study was approved and supported by the IPC. The authors would like to thank the POCOG staff, as well as the NPC medical staff, whose input was pivotal to the success of this study.

\section{Ethical approval}

Research Ethical Approval was granted by the University of Brighton (FREGS/ES/12/11) and Stellenbosch University (N16/05/067).

\section{Patient involvement}

No.

\section{Contributorship}

All authors have contributed to the development, application and write up of the current study. Each author has completed a Conflicts of Interest form.

\section{Conflicts of interest}

All authors have declared competing interests. 


\section{Funding}

Funding for this study was provided by the International Olympic Committee (IOC) Research Centre South Africa grant and International Paralympic Committee research support. 


\section{REFERENCE LIST}

1 Derman W, Schwellnus M, Jordaan E, et al. Illness and injury in athletes during the competition period at the London 2012 Paralympic Games: development and implementation of a web-based surveillance system (WEB-IISS) for team medical staff. Br J Sports Med 2013;47:420-5. doi:10.1136/bjsports-2013-092375

2 Schwellnus M, Derman W, Jordaan E, et al. Factors associated with illness in athletes participating in the London 2012 Paralympic Games: a prospective cohort study involving 49,910 athlete-days. Br J Sports Med 2013;47:433-40. doi:10.1136/bjsports2013-092371

3 Blauwet C, Lexell J, Derman W, et al. The Road to Rio: Medical and Scientific Perspectives on the 2016 Paralympic Games. PM R 2016;8:798-801. doi:10.1016/j.pmrj.2016.07.004

4 Derman W, Schwellnus MP, Jordaan E, et al. Sport, sex and age increase risk of illness at the Rio 2016 Summer Paralympic Games: a prospective cohort study of 51198 athlete days. Br J Sports Med 2018;52. doi:10.1136/bjsports-2017-097962

5 Derman W, Schwellnus M, Jordaan E. Clinical characteristics of 385 illnesses of athletes with impairment reported on the web-iiss system during the london 2012 paralympic games. PM R 2014;6:S23-30. doi:10.1016/j.pmrj.2014.05.016

6 Derman W, Schwellnus MP, Jordaan E, et al. The incidence and patterns of illness at the Sochi 2014 Winter Paralympic Games: a prospective cohort study of 6564 athlete days. Br J Sports Med 2016;:bjsports-2016-096215. doi:10.1136/bjsports-2016-096215

7 Fagher K, Jacobsson J, Timpka T, et al. The Sports-Related Injuries and Illnesses in Paralympic Sport Study ( SRIIPSS ): a study protocol for a prospective longitudinal study. BMC Sports Sci Med Rehabil 2016;:1-10. doi:10.1186/s13102-016-0053-x

8 Derman W, Schwellnus MP, Jordaan E, et al. The incidence and patterns of illness at the Sochi 2014 Winter Paralympic Games: A prospective cohort study of 6564 athlete days. Br J Sports Med 2016;50. doi:10.1136/bjsports-2016-096215

9 Bahr R, Clarsen B, Ekstrand J. Why we should focus on the burden of injuries and illnesses, not just their incidence. Br J Sports Med 2018;52:14-7. doi:10.1136/bjsports2017-098160

10 Stovitz SD, Shrier I. Injury rates in team sport events: Tackling challenges in assessing exposure time. Br J Sports Med 2012;46:960-3. doi:10.1136/bjsports-2011-090693

11 Bonini M, Gramiccioni C, Fioretti D, et al. Asthma, allergy and the Olympics. Curr 
Opin Allergy Clin Immunol 2015;15:184-92. doi:10.1097/ACI.0000000000000149

12 Soligard T, Steffen K, Palmer-Green D, et al. Sports injuries and illnesses in the Sochi 2014 Olympic Winter Games. Br J Sports Med 2015;:1-9. doi:10.1136/bjsports-2014094538

13 Engebretsen L, Steffen K, Alonso JM, et al. Sports injuries and illnesses during the Winter Olympic Games 2010. Br J Sports Med 2010;44:772-80.

doi:10.1136/bjsm.2010.076992

14 Bayne H, Schwellnus M, Janse Van Rensburg D, et al. Incidence of injury and illness in South African professional male football players: a prospective cohort study. $J$ Sports Med Phys Fitness 2017;ePub:ePub-ePub. doi:10.23736/S0022-4707.17.074527

15 Schwabe K, Schwellnus M, Derman W, et al. Medical complications and deaths in 21 and $56 \mathrm{~km}$ road race runners: A 4-year prospective study in 65865 runners-SAFER study i. Br J Sports Med 2014;48:912-8. doi:10.1136/bjsports-2014-093470

16 Orchard J, Hoskins W. For debate: Consensus injury definitions in team sports should focus on missed playing time. Clin J Sport Med 2007;17:192-6. doi:10.1097/JSM.0b013e3180547527

17 Brooks JHM, Fuller CW, Kemp SPT, et al. Epidemiology of injuries in English professional rugby union: Part 1 match injuries. Br J Sports Med 2005;39:757-66. doi:10.1136/bjsm.2005.018135

18 Williams S, Trewartha G, Kemp SPT, et al. Time loss injuries compromise team success in Elite Rugby Union: A 7-year prospective study. Br J Sports Med 2016;50:651-6. doi:10.1136/bjsports-2015-094798

19 Quarrie KL, Hopkins WG. Tackle injuries in professional rugby union. Am J Sports Med 2008;36:1705-16. doi:10.1177/0363546508316768

20 Brooks JHM, Fuller CW, Kemp SPT, et al. Epidemiology of injuries in English professional rugby union: Part 2 training injuries. Br J Sports Med 2005;39:767-75. doi:10.1136/bjsm.2005.018408

21 Brooks JHM, Kemp SPT. Injury-prevention priorities according to playing position in professional rugby union players. Br J Sports Med 2011;45:765-75. doi:10.1136/bjsm.2009.066985 